Niña Eliza R. Pernia, MD' Joseph Amado C. Galvez, MD ${ }^{1,2}$

Francisco A.Victoria, MD ${ }^{1,3,4}$

'Department of Otorhinolaryngology

Head and Neck Surgery

Ospital ng Maynila Medical Center

${ }^{2}$ Department of Otorhinolaryngology Head and Neck Surgery

The Medical City

${ }^{3}$ Department of Otorhinolaryngology Head and Neck Surgery

Quezon City General Hospital

${ }^{4}$ Department of Otorhinolaryngology Head and Neck Surgery

Medical Center Manila
Correspondence: Dr. Niña Eliza R. Pernia Department of Otorhinolaryngology

Ospital ng Maynila Medical Center

Roxas Blvd cor. Quirino Ave., Malate, Manila 1000 Philippines

Phone: 5246061 local 220

Fax: 5236681

Reprints will not be available from the author.

The authors declared that this represents original material that is not being considered for publication or has not been published or accepted for publication elsewhere, in full or in part, in print or electronic media; that the manuscript has been read and approved by all the authors, that the requirements for authorship have been met by each author, and that each author believes that the manuscript represents honest work.

Disclosures: The authors signed disclosures that there are no financial or other (including personal) relationships, intellectual passion, political or religious beliefs, and institutional affiliations that might lead to a conflict of interest.

Presented at the Descriptive Research Contest, Philippine Society of Otolaryngology Head and Neck Surgery, Glaxo Smith Kline (GSK) Bldg., Chino Roces Ave., Makati City Philippines, October 11, 2010

\title{
The Dimensions of the Nasal Septal Cartilage: A Preliminary Study in Adult Filipino Malay Cadavers
}

\begin{abstract}
Objectives: This study aimed to measure the dimensions of the nasal septal cartilage in adult Filipino Malay cadavers and calculate the cartilage area as well as the amount of graft material that can be harvested from the septal cartilage.
\end{abstract}

\section{Methods:}

Design: Descriptive, cross-sectional

Setting: Pamantasan ng Lungsod ng Maynila College of Medicine Anatomy Laboratory

Subjects: Ten preserved adult cadavers dissected within a period from September 2010 to October 2010. The septal cartilages were harvested and the lengths of the cephalic margin, dorsal margin, caudal margin and ventral margin were measured. From these measurements, the total area of the cartilage and the amount of graft material that can be harvested were calculated.

Results: The mean length of each margin of the septal cartilage was $25.9 \mathrm{~mm}$ (cephalic edge), $22.3 \mathrm{~mm}$ (dorsal edge), $21.4 \mathrm{~mm}$ (caudal edge) and $33.1 \mathrm{~mm}$ (ventral edge). The area of the septal cartilage had a mean value of $652.5 \mathrm{~mm}^{2}$. The amount of septal cartilage which can be harvested had a mean area of $403 \mathrm{~mm}^{2}$.

Conclusion: This study showed a slight decrease in septal cartilage area to $652.5 \mathrm{~mm}^{2}$ and in available graft material to $403 \mathrm{~mm}^{2}$. While this decrease may reflect the apparently smaller noses of native Southeast Asians compared to East Asians and South Asians, the difference in values can also be due to the difference in the number of subjects or in methods of measurement and further studies are recommended to determine the extent of inter-racial variability.

\section{Keywords: septal cartilage, autologous graft}

The septal cartilage is a widely used autologous graft and is generally accepted as the gold standard of grafting materials. 'Its main use is in septorhinoplasty and as a spreader graft to widen the internal nasal valve to treat nasal obstruction. ${ }^{2}$ The effects of cartilage tympanoplasties on tympanic membrane closure, hearing improvement and prevention of retraction pockets have been well documented. ${ }^{3,45}$ It can even be applied to reconstruction of the orbital floor. ${ }^{6}$ 
ORIGINAL ARTICLES

Studies on the dimensions of the septal cartilage have been done in several countries using both cadavers and radiographic images to establish a baseline measurement distinct to their race. In 1997, Godley collected anatomic data from 60 cadavers, mostly Caucasians.? Another study in Korea used MRI images to determine the area of the nasal septum and grouped them according to age ${ }^{7}$. However, despite the increasing popularity of autologous grafts in our country, we are not aware of locally published studies on the subject. For instance, the generally smaller Southeast Asian noses of many Malay Filipinos may not yield as much septal cartilage as the noses of East (North China, Japan, Korea) and South (India) Asians or Caucasians.

This study aimed to measure the dimensions of the nasal septal cartilage in Filipino Malay cadavers and calculate the cartilage area and the amount of graft material that can be harvested from the septal cartilage.

\section{METHODS}

This was a cross-sectional study. Ten adult preserved cadavers (6 males, 4 females) were dissected in the Pamantasan ng Lungsod $n g$ Maynila Anatomy Laboratory between September and October 2010 by two ORL residents. In each cadaver, an open sky rhinoplasty technique was used. A small incision was made in the columella, the columellar flap was then elevated to expose the alar and septal cartilages. The septal cartilages were dissected from the perichondrium and harvested.

The cephalic, dorsal, caudal and ventral lengths were measured accordingly using a standard ruler in millimeters (Figure 1), the area

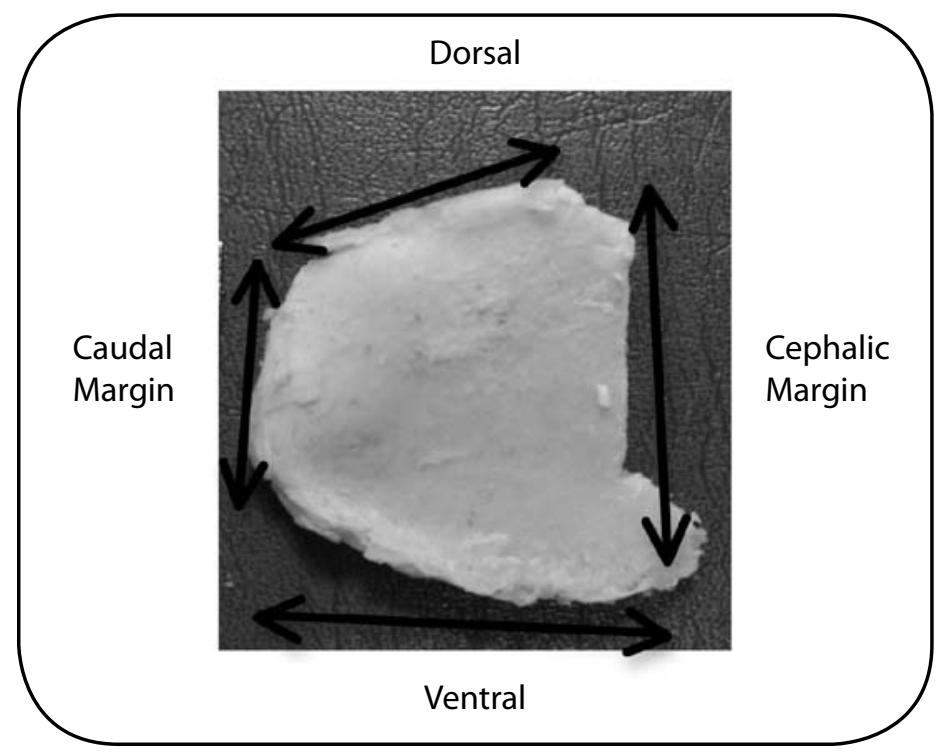

Figure 1. The Margins of the Nasal Septum of each septum was measured (Figure 2) by dividing the septum into two triangles and applying the formula for area of a triangle to each. From these values, the amount of graft material that can be harvested (excluding the $1 \mathrm{~cm}$. dorsal-caudal L-strut) was computed using the formula for determining the area of irregular shapes, derived from the Pythagorean Theorem (BH/2) (Figure 3).

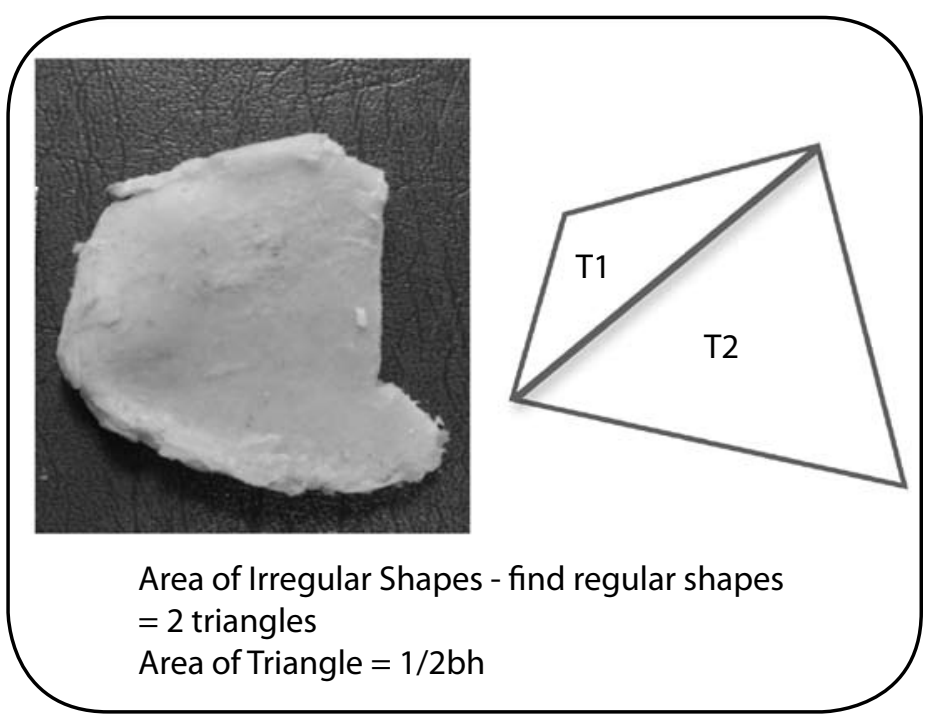

Figure 2. Computation of NasalSeptal Area

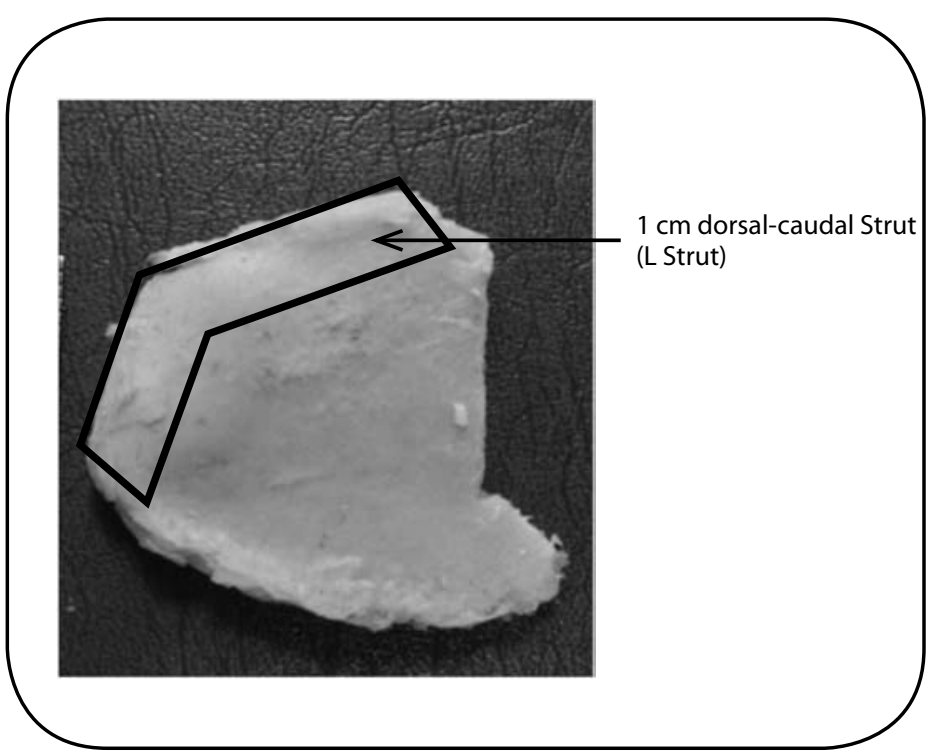

Figure 3. Septal Cartilage with L Strut 


\section{ORIGINAL ARTICLES}

\section{RESULTS}

The mean lengths of the margins of the septal cartilage were: 25.9 $\mathrm{mm}$, cephalic margin (range: $23-28 \mathrm{~mm}$ ), $22.3 \mathrm{~mm}$ dorsal margin (range $20-26 \mathrm{~mm}$ ), $21.4 \mathrm{~mm}$ caudal margin (range: $19-25 \mathrm{~mm}$ ) and $33.1 \mathrm{~mm}$ ventral margin (range: $30-36 \mathrm{~mm}$ ). The mean area of the septal cartilage was $652.5 \mathrm{~mm}^{2}$ and the mean amount of cartilage which can be harvested was $403 \mathrm{~mm}^{2}$.

\section{DISCUSSION}

This study measured the dimensions of the nasal septal cartilage in Filipino Malay cadavers and calculated the cartilage area and the amount of graft material that can be harvested from the septal cartilage. The cartilage area of the septum includes the whole quadrangular cartilage dissected from all its attachments. The amount of available graft material is the area of the septum without the $1 \mathrm{~cm}$ dorsal-caudal strut (or L strut).

A recent study measuring nasal cartilage by Kim, et al in Korea used MRI sagittal sections of 280 patients. ${ }^{7}$ The adult septum was noted to have a mean measurement of $692 \mathrm{~mm}^{2}$ with a maximal amount of graft material of $427 \mathrm{~mm}^{2} .7$ This is not far from the value of $420 \mathrm{~mm}^{2}$ of graft material (excluding the $L$ strut) obtained by Miles et al. ${ }^{8}$ Our study showed a slight decrease in septal cartilage area to $652.5 \mathrm{~mm}^{2}$ and in available graft material to $403 \mathrm{~mm}^{2}$. While this decrease may reflect the apparently smaller noses of native Southeast Asians compared to East Asians and South Asians, the difference in values can also be due to the difference in the number of subjects, as this study only utilized 10 cadavers. In addition, the study done in Korea was based on radiologic images rather than cadaver dissection. In 1997, Godley et al. studied the noses of 60 adult cadavers and reported the cartilaginous dorsal length to be $21 \pm 5 \mathrm{~mm}$ on average (shorter in females by approximately $5 \pm 4 \mathrm{~mm}$ ). ${ }^{7}$ Kim's study which was based on radiological measurements yielded a cartilage dorsal length in adults of $26 \pm 4 \mathrm{~mm}$ on average with no significant differences in dorsal length between males and females. ${ }^{7}$ In this study, the mean dorsal length was $22.3 \mathrm{~mm}$, closer to the cadaver values reported by Godley.

Septal cartilage may be available in different populations as graft material if less than $400 \mathrm{~mm}^{2}$ is needed and further studies can determine the extent of inter-racial variability. Surgeons can then decide if septal cartilage is enough or additional donor sites are needed and patients can be oriented regarding these additional surgeries preoperatively.

In addition, knowledge of the area available to the surgeon can lessen the possibility of extensive resection of the nasal septum. Too much resection can lead to weakening of the structural support of the nose which can bring about saddle nose deformity and problems in airway function. Studies such as this are valuable to basic and applied medical science.

This study was limited to the 2-dimensional plane of the nasal septum and was not able to determine its actual surface area and thickness which can be valuable in nasal airflow studies. The computation for the area of irregular shapes used in this study only yields approximate values and future studies may employ more accurate centimeter grids to measure area. Thickness, which varies from caudal edge to posterior attachment can also be evaluated. Areas based on cadaver dissection can also be compared with those obtained from imaging modalities.

The limited number of subjects in this study did not allow stratification according to age or sex. The observation that the septum is actually bigger in younger populations (who are also generally taller than previous generations) and in noses with long columellas (especially in mestizos or those of mixed-heritage) can be validated. While the data gathered in this study is comparable to that available in the literature, further studies with more subjects utilizing harvested septal cartilage are needed to validate existing data and posit predictive parameters for the size of the septum.

\section{ACKNOWLEDGEMENTS}

The author would like to acknowledge Dr. Jenny Catignas for her assistance in the dissections.

\section{REFERENCES}

1. Lin G, Lawson W. Complications using grafts and implants in rhinoplasty. Operative Techniques in Otolaryngology. $2007 \mathrm{Dec} ; 18: 315-23$.

2. Fischer $\mathrm{H}$, Gubisch W. Nasal valves--importance and and surgical procedures. Facial Plast Surg. 2006 Nov;22(4):266-80. 2006 Nov;22(4):266-80.

3. Yung M. Cartilage tympanoplasty: literature review. J Laryngol Otol. 2008 Jul; 122(7): 663-72. Epub 2008 Mar 3.

4. Aarnisalo AA, Cheng JT, Ravicz ME, Hulli N, Harrington EJ, Hernandez-Montes MS, et al. Middle ear mechanics of cartilage tympanoplasty evaluated by laser holography and vibrometry, Otol Neurotol 2009 Dec; 30(8): 1209-14.

5. Ozbek C, Ciftçi O, Ozdem C. Long-term anatomic and functional results of cartilage tympanoplasty in atelectatic ears. Eur Arch Otorhinolaryngol. 2010 Apr; 267(4): 507-13. Epub 2009 Sep 2.

6. Cavusoglu,T, Vargel I, Yaziqi I, Cavusoglu M, Vural AC. Reconstruction of orbital floor fractures using autologous nasal septal bone graft. Ann Plast Surg 2010 Jan ;64 (1):41-6.

7. Kim IS, Lee MY, Lee KI, Kim,HY, Chung YJ. Analysis of the development of the nasal septum according to age and gender using MRI. Clin Exp Otorhinolaryngol. 2008 Mar; 1(1): 29-34. Epub 2008 March 20. [cited 2010 August]. Available from: http://www.ncbi.nlm.nih.gov/pmc/articles/ PMC2671753

8. Miles BA, Petrisor D, Kao H, Finn RA, Throckmorton GS. Anatomical variation of the nasal septum: analysis of 57 cadaver specimens. Otolaryngol Head Neck Surg. 2007 Mar;136(3):362-368. 